\title{
Pendekatan Kearifan Lokal pada Aspek Sosial di Wisata Malam Kota Berastagi
}

\author{
Selly Veronica ${ }^{1}$, Nurlisa Ginting ${ }^{2}$, Amy Marisa ${ }^{3}$ \\ 1,2,3 Program Studi Magister Teknik Arsitektur, Fakultas Teknik, Universitas Sumatera Utara,Medan, \\ Indonesia, email: selly.veronica@students.usu.ac.id \\ ${ }_{1,2,3}$ Monitoring Centre for Sustainable Tourism Observatory Universitas Sumatera Utara, Medan, \\ Indonesia
}

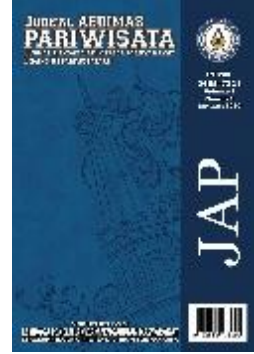

\begin{tabular}{|c|c|}
\hline Informasi artik & \\
\hline $\begin{array}{l}\text { Sejarah } \\
\text { artikel }\end{array}$ & \\
\hline Diterima & : 01Juli 2020 \\
\hline Revisi & : 15Juli 2020 \\
\hline Dipublikasikan & : 30 Juli 2020 \\
\hline
\end{tabular}

\section{Kata kunci:}

Wisata Malam

Sosial

Kearifan Lokal

Berastagi

\begin{abstract}
ABSTRAK
Pariwisata merupakan sektor strategis yang menjadi bagian penting dalam pengembangan kota. Wisata malam adalah jenis pariwisata yang inovatif dan potensial untuk dikembangkan. Berastagi dikenal sebagai salah satu tujuan wisata populer di Sumatera Utara yang telah memiliki wisata malam. Tetapi saat ini citra negatif dari wisata malam yang melekat dalam kehidupan sosial masyarakat selalu menjadi hambatan pada proses pengembangannya. Menerapkan pendekatan kearifan lokal pada aspek sosial wisata malam penting untuk dilakukan demi terciptanya pengembangan yang harmonis antara wisata malam dan masyarakat. Analisa deskriptif kualitatif telah dilakukan dengan menggunakan metoda pengumpulan data secara wawancara dan observasi lapangan. Hasil dari penelitian ini menunjukan bahwa kearifan lokal menjadi kekuatan dan proteksi yang dimiliki masyarakat untuk mendukung pengembangan wisata malam di Kota Berastagi.

ABSTRACT

Local Wisdom Approach on Social Aspect in Berastagi Night Tourism

Tourism is a strategic sector that becomes a significant part of urban development. Night tourism is the kind of tourism which innovative and potential to develop.Berastagi is known as one of the popular tourist destinations in North Sumatra that has night tourism.But nowadays, the negative image of night tourism that attaches to community life always be the obstacle in its developing process. Applying the local wisdom approach in the social aspect of night tourism is necessary to be held to create harmony between the night tourism and community. The descriptive qualitative analysis has been carried out using the data collecting method by interview and field observation. This study shows local wisdom be the strength and protection that the community has to support the night tourism development in Berastagi.
\end{abstract}

Keywords:

Night Tourism

Social

Local Wisdom

Berastagi

\section{Pendahuluan}

Pariwisata mampu memberikan manfaat ekonomi dan sosial yang meningkatkan kualitas hidup masyarakat sekitarnya. Pada beberapa negara di dunia, pariwisata bahkan menjadi sumber ekonomi terbesar. Manfaat yang dijanjikan dari pengembangan pariwisata suatu kota menjadikannya sebagai bagian yang penting dalam pengembangan kota (Bălan \& Burghelea, 2015; Glaesser et al., 2017; Goh, 2015; Wolifson, 2016). Tidak hanya di Dunia, namun setiap Kota yang ada di Indonesia juga sedang berlomba untuk membenahi dan memperkuat destinasi wisata yang dimilikinya. Ditengah sengitnya persaingan pariwisata, wisata malam hadir sebagai inovasi baru yang potensial untuk dikembangkan (Aytuğ \& Mikaeili, 2017; Rodrigues et al., 2015; Wolifson \& Drozdzewski, 2017). Wisata malam hadir dari adanya kebiasaan baru wisatawan yang ingin memaksimalkan setiap waktu yang ia miliki dalam mengunjungi suatu tempat. Perjalanan wisata malam dilakukan untuk menikmati kegiatankegiatan sederhana seperti berbelanja, mencari makanan atau hanya sekedar berjalan-jalan santai (Lee et al., 2008). 
Hadirnya kebiasaan baru wisatawan tersebut menciptakan peluang yang strategis dalam pengembangan pariwisata. Tidak hanya dapat memenuhi kebutuhan wisatawan, namun wisata malam juga menjadi solusi dalam upaya peningkatan nilai dan fungsi lahan pada suatu kawasan (Zaki \& Ngesan, 2012).

Pada upaya pengembangan potensi wisata malam, para penentu kebijakan seharusnya tidak hanya mempertimbangkan dampak positifnya. Wisata malam yang identik dengan kegelapan dan aktivitas malam juga memiliki dampak negatif yang harus dipertimbangkan. Dampak negatif tersebut berupa gambaran kegiatan malam yang sering diidentikan dengan aktivitas yang bertentangan dengan kehidupan sosial masyarakat sertanilai dan norma yang berlaku(Ngesan \& Karim, 2012). Sedangkan, citra positif dari suatu destinasi wisata merupakan hal yang sangat penting terutama dalam strategi pemasarannya (Widiastini et al., 2020). Persepsi negatif masyarakat terhadap kegiatan wisata malam selalu menjadi hambatan dalam suatu kawasan untuk mengembangkan potensi wisata malamnya. Aspek sosial berperan penting dalam pengembangan wisata malam, dimana aspek ini sangat rentan terhadap dampak negatif dari suatu pengembangan wisata malam. Melalui upaya manajemen aspek sosial maka para penentu kebijakanakan dapat mengharmonikan aktivitas wisatawan dengan kehidupan masyarakat (Aytuğ \& Mikaeili, 2017; Nofre et al., 2018).

Kota Berastagi adalah kota wisata yang juga menjadi salah satu destinasi wisata populer di Kabupaten Karo, Sumatera Utara,Indonesia. Jarak Kota Berastagi denganKota Medan yang merupakan Ibu Kota Provinsi Sumatera Utarahanya sejauh $\pm 60 \mathrm{~km}$, sehingga kota ini mudah untuk dijangkau. Kemudahan aksesibilitas Kota Berastagi menjadi daya tarik tersendiri sehingga kota wisata ini banyak diminati oleh wisatawan domestik dan mancanegara. Tidak hanya memiliki pemandangan alam yang indah, Kota Berastagi juga telah memiliki tujuan wisata malam yang dapat dinikmati wisatawan. Namun sangat disayangkan, hingga saat ini wisata malam yang terdapat di Kota Berastagi belum dikembangkan secara maksimal. Aspek sosial masyarakat yang memiliki persepsi negatif terhadap wisata malam menjadi penghambat berkembangnya potensi tersebut.

Penanganan dampak negatif pada aspek sosial pengembangan wisata malam dapat dilakukan dengan menerapkan pendekatan berbasis kearifan lokal. Kearifan lokal merupakan manifestasi dari pola interaksi antara manusia dan alam yang membentuk perilaku dan diteruskan secara turun-temurun (Singsomboon, 2014; Veronica et al., 2019; Vitasurya, 2016). Bentuk lain dari kearifan lokal berupa ritual budaya, kesenian, sistem kepercayaan, dan pengetahuan lokal yang dimiliki suatu komunitas (Jupir, 2013). Penerapan kearifan lokal pada pengembangan kawasan dapat menjadi kekuatan yang menjaga keseimbangan, sehingga manusia dapat melakukannya dengan lebih bijak (Farhan \& Anwar, 2016).

Suku Karo merupakan suku mayoritas masyarakat yang tinggal di Kota Berastagi. Kearifan lokal yang muncul dari Budaya Karo dapat menjadi bagian dari identitas Kota Berastagi. Sudah seharusnya pengembangan wisata malam Kota Berastagi dilakukan dengan pendekatan kearifan lokalnya, sehingga aspek sosial yang tercipta menjadi lebih positif. Dalam upaya mewujudkan hal tersebut, perlu adanya kajian pendekatan kearifan lokal pada aspek wisata malam Kota Berastagi. Kegiatan pengabdian ini bertujuan untuk menghasilkan gagasan yang dapat dijadikan landasan oleh masyarakat dan para penentu kebijakan dalam memaksimalkan potensi wisata malam Kota Berastagi.

\section{Metode}

Pada kegiatan pengabdian masyarakat ini digunakan metoda analisa deskriptif, dimana tahap yang dilakukan adalah identifikasi, diskusi, dan analisa kebijakan(Kiswantoro et al., 2020). Proses identifikasi permasalahan yang terdapat pada aspek sosial di wisata malam Kota Berastagi dilakukan dengan observasi lapangan. Hal ini ditujukan untuk mendokumentasikankondisi fisik wisata malam Kota Berastagi dan memberikantimgambaran dasar kondisi yang terjadi di kawasan tersebut. Diskusi dilakukan dengan cara wawancara mendalam dengan 8 orang narasumber utama yang terdiri dari kelompok budaya, pemerintah, dan pelaku usaha wisata malam (Ngesan \& Karim, 2012). Kedelapan narasumber utama yang terlibat dan memberikan gagasan pada kegiatan ini adalah:

\section{Ketua Ketua Ikatan Cendikiawan Karo Sumatera Utara (ICKSU),}

2. Kepala Badan Perencanaan Pembangunan Daerah (BAPPEDA) Kabupaten Karo, 
3. Ketua Perhimpunan Hotel dan Restoran Indonesia (PHRI) Kabupaten Karo,

4. Ka. Bid. Seni dan Kebudayaan pada Dinas Pariwisata dan Kebudayaan Kabupaten Karo

5. Pedagang dan Sekertaris Asosiasi Pedagang Pasar Kaget,

6. Ka. Bid. Pengembangan Pemasaran pada Dinas Pariwisata dan Kebudayaan Kabupaten Karo,

7. Pengusaha Kafe Pertama Kota Berastagi, dan

8. Pemimpin Sanggar Seni Karo Persada dan ketua Lembaga Adat dan Budaya Karo (Lakonta).

Pelaksanaan observasi lapangan dan wawancara mendalam guna mengumpulkan data pada tahap identifikasi dan diskusi dilakukan dengan berlandaskan pada indikator yang telah dirumuskan sebelumnya. Rumusan indikator didahului dengan kajian literatur terhadap teori kearifan lokal dan teori aspek sosial wisata malam (Tabel 1).

Tabel 1. Nama tabel

\begin{tabular}{cl}
\hline Variabel & \multicolumn{1}{c}{ Indikator } \\
\hline Proteksi sosial & Masyarakat memproteksi sosial wisata malam dengan nilai kehidupan suku Karo \\
\hline Budaya Lokal & Pengaruh dari aktivitas wisata malam terhadap budaya masyarakat lokal \\
\cline { 2 - 2 } & Keterlibatan budaya Karo pada pengembangan wisata malam \\
\hline Pengalaman & Pengalaman baru yang dapat dirasakan wisatawan \\
\cline { 2 - 2 } Baru & Kegiatan yang unik yang ditawarkan wisata malam pada pengunjung \\
\hline Aktivitas & Jenis kegiatan pengunjung pada wisata malam \\
\cline { 2 - 2 } Wisatawan & Waktu wisatawan memulai perjalanan wisata malamnya \\
\hline
\end{tabular}
Sumber : Data Primer (2019)

Hasil pemikiran dari masing-masing narasumber dianalisa untuk menghasilkan gagasan-gagasan yang dapat menjadi dasar kebijakan dalam penerapan kearifan lokal pada aspek sosial di wisata malam Kota Berastagi.

\section{Hasil dan Pembahasan}

Berastagi merupakan salah satu kota wisata yang memiliki keindahan alam dan kesejukan udara yang banyak dinikmati oleh wisatawan. Berada di atas ketinggian yang lebih dari 1300 mdpl, serta dikelilingi oleh pegunungan menjadikan kota ini sebagai salah satu kota terdingin yang ada di Indonesia. Lokasi Kota Berastagi yang berada diantara Kota Medan dan Kawasan Kaldera Toba yang merupakan salah satu destinasi wisata prioritas nasional membuatnya menjadi sangat tepat diperuntukan sebagai Kota Persinggahan bagi wisatawan yang berkunjung. Wisatawan yang datang berkunjung ke Kota Berastagi adalah wisatawan nusantara dan wisatawan mancanegara yang datang dari negara tetangga (Malaysia \& Singapura) dan negera-negara di Eropah (Jerman, Belanda, Prancis, dll). Selain menawarkan pemandangan alamnya yang indah, Kota Berastagi juga telah memiliki destinasi wisata malam yang berada tepat di pusat kotanya. Terdapat tiga jenis kegiatan wisata malam yang dapat dilakukan saat ini, yaitu, berbelanja makanan yang ada di pusat kuliner yang dikenal dengan Pasar Kaget, menikmati kopi khas Kabupaten Karo di kafe yang tersedia, dan berjalan-jalan di Taman Mejuah-juah (Gambar 1). 


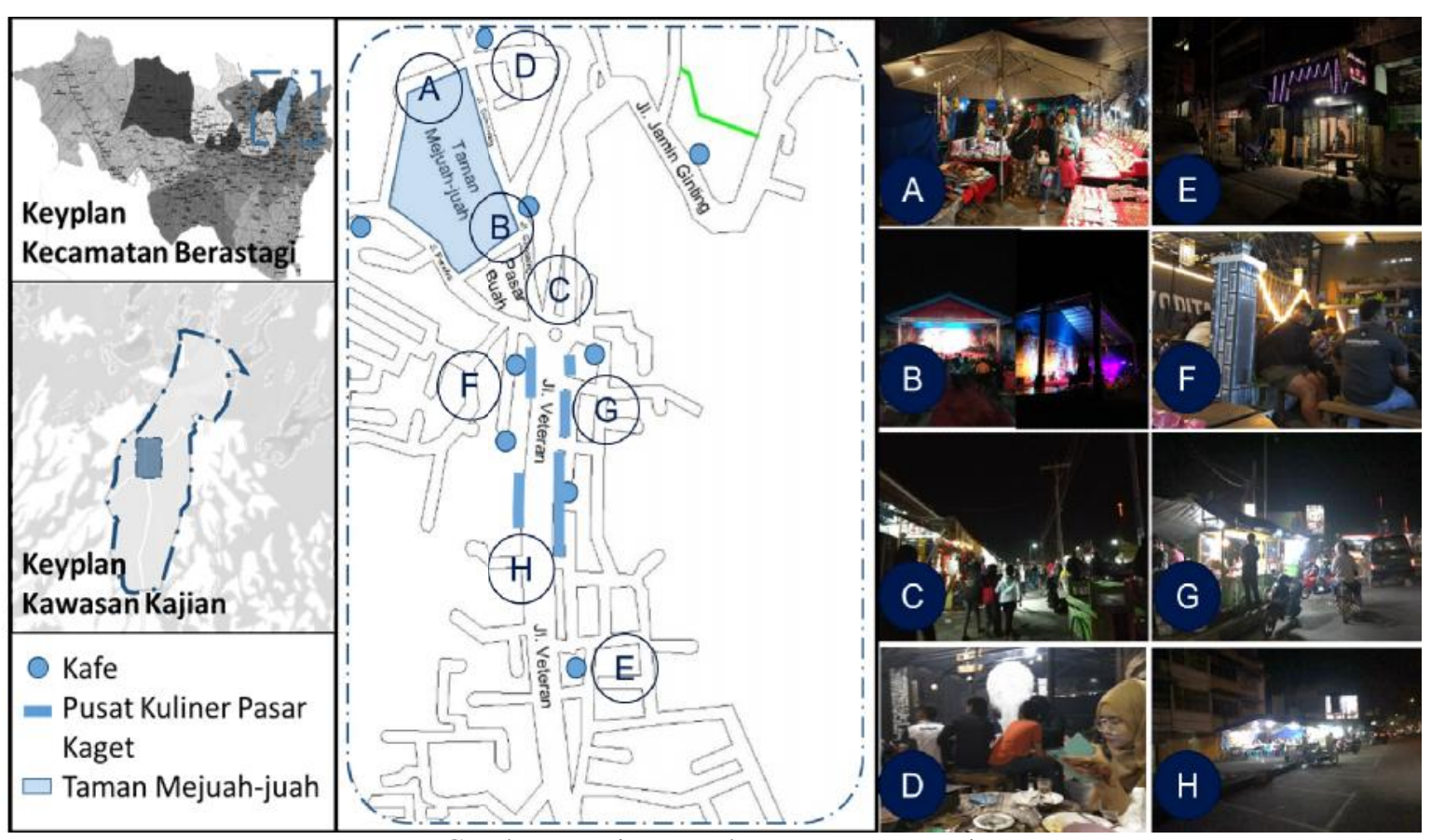

Gambar 1. Wisata Malam Kota Berastagi

Kafe sudah menjadi bagain dari gaya hidup masyarakat hingga pada masa kini. Peluang dari popularitas kopi yang banyak diminati masyarakat khususnya yang berusia muda mendorong para pengusaha untuk mengembangkan potensi tersebut. Kabupaten Karo memiliki produk kopi yang berkualitas sehingga terkenal di pasar nasional dan internasional. Para pengusaha muda di Kota Berastagi memanfaatkan potensi dari kopi yang ada di Kabupaten Karo dengan mendirikan kafe yang menyuguhkan kopi khas untuk dinikmati oleh wisatawan. Hidangan kopi hangat sangat cocok dengan cuaca Kota Berastagi yang dingin pada malam hari. Selain kafe, Pasar Kaget sebagai pusat kuliner Kota Berastagi yang hanya ditemukan pada malam hari juga menjadi tujuan para wisatawan. Pasar Kaget terdiri dari deretan stan makanan yang berdiri diatas jalur pedestrian Kota Berastagi. Wisatawan dapat menikmati hidangan nusantara dan jajanan pasar yang sangat beragam. Taman Mejuah-juah yang merupakan ruang terbuka hijau Kota Berastagi juga dapat digunakan sebagai tujuan wisata malam. Namun sangat disayangkan, saat ini wisatawan hanyadapat menikmati wisata malam di Taman Mejuah-juah pada waktu-waktu tertentu saja. Suasana wisata malam di Taman Mejuah-juahhanya dapat dinikmati pada saat adanya event-event tahunan seperti Perayaan Kemerdekaan Indonesia, Festival Bunga dan Buah, dan Festival Budaya.

Aktivitas wisata yang dapat dilakukan wisatawan dalam menikmati waktu malam harinya di Kota Berastagi masih sangat terbatas. Menurut penuturan kepala BAPPEDA Kab. Karo, pengembangan wisata malam Kota Berastagi terhambat oleh adanya stigma negatif masyarakat terhadap aktivitas pada malam hari. Aktivitas ekonomi wisata malam kerap kali diidentikan dengan aktivitas-aktivitas negatif pub, diskotik, dan tempat penjualan minuman keras(Ngesan \& Karim, 2012). Pengembangan wisata malam Kota Berastagi harus mempertimbangkan aspek sosialnya dengan menerapkan kearifan lokal yang tumbuh di kehidupan masyarakat. Masyarakat Kota Berastagi masih memegang teguh nilai dan norma-norma yang ada pada kebudayaan mereka yaitu Budaya Karo.

Mayoritas masyarakat di Kota Berastagi yang bersuku Karomasih sangat menjunjung tinggi tradisi yang mereka miliki. Sebagai upaya proteksi budaya yang ada di masyarakat maka terbentuklah suatu lembaga adat yang disebut dengan Lakonta (Lembaga Adat dan Budaya Karo). Lakonta terdiri dari tokoh-tokoh adat yang berperan sebagai lembaga yang menjaga agar kondisi sosial masyarakat tetap berjalan dengan sebagaimana mestinya. Selain adanya lembaga adat, masyarakat juga memiliki budaya Mehangke dan Sihangke dalam kehidupan sosialnya. Budaya ini merupakan bentuk dari kebiasaan masyarakat Karo yang membudayakan rasa malu untuk melakukan aktivitas yang tidak baik. Kedekatan antar masyarakat yang masih saling mengenal antara satu dengan yang lainnya juga 
menjadi alasan mengapa budaya Mehangke dan Sihangke tetap bertahan hingga saat ini. Wisatawan pada dasarnya memiliki latar belakang budaya yang berbeda dengan masyarakat, sehingga terkadang terdapat kebiasaan wisatawan dalam berwisata malam yang tidak sejalan dengan budaya kehidupan lokal. Kearifan lokal masyarakat merupakan tameng yang paling kuat dalam menjaga sosial masyarakat dari dampak negatif yang muncul dari aktivitas wisatawan (Roberts \& Eldridge, 2007; Vitasurya, 2016). Budaya Karo yang masih kuat dan diterapkan pada masyarakat hingga saat ini dapat menjadi proteksi sosial masyarakat dalam mengatasi persepsi negatif yang muncul dari aktivitas wisata malam.

Meskipun masyarakat memiliki pandangan negatif terhadap kegiatan wisata malam, namun hingga saat ini belum ditemukan kasus dimana terdapat dampak aktivitas wisatawan yang merugikan masyarakat. Pasar wisata Kota Berastagi yang banyak diminati oleh wisatawan Eropah menyebabkan tumbuhnya permintaan dan kebutuhan wisatawan yang sesuai dengan budaya mereka. Wisatawan Eropah pada umumnya memiliki kebiasaan untuk meminum minuman beralkohol pada malam hari. Aktivitas wisatawan dalam menikmati wisata malam terkadang tidak sejalan dengan kehidupan masyarakat lokal. Seperti halnya minuman beralkohol yang dianggap wajar oleh wisatawan Eropah, namun bagi mayoritas masyarakat yang berbudaya timur hal tersebut masih dianggap tabu (Nofre et al., 2018; Yeo \& Heng, 2014). Kebiasaan wisatawan dalam menikmati wisata malam yang ada di Kota Berastagi masih berada dalam batas kewajaran. Meskipun wisatawan menikmati minuman beralkohol pada malam hari namun hal ini tidak pernah menganggu ketentraman dan kenyamanan masyarakat yang berada di sekitar kawasan wisata. Lembaga adat budaya Karo juga secara aktif memantau aktivitas tersebut. Lakonta berperan aktif dalam mengkontrol kondisi sosial masyarakat agar tidak terjadi pergeseran budaya dan tetap terikat pada Budaya Karo.

Pada dasarnya minuman beralkohol bukan menjadi hal yang baru bagi masyarakat Karo, dimana para pria Suku Karo juga mengkonsumsinya. Budaya Karo memiliki sejenis minuman beralkohol yang dikenal dengan Tuak. Minuman ini merupakan hasil fermentasi air nira yang juga menjadi bagian dari kehidupan berbudaya masyarakat Suku Karo. Cara masyarakat mengontrol konsumsi Tuak agar tetap berada dalam tingkat kesadaran yang tidak membahayakan sekitar juga dapat diterapkan pada wisatawan. Selain itu kehadiran Tuak juga dapat memberikan pengalaman baru bagi wisatawan untuk dapat menikmati minuman beralkohol khas Kota Berastagi. Kecenderungan wisatawan adalah datang berkunjung kesuatu tempat yang berbeda dari kesehariannya.Kebiasaan dan budaya khas yang dimiliki suatu komunitas akan memberikan pengalaman baru yang mampu menarik minat wisatawan untuk berkunjung (Damasdino et al., 2020; Markwick, 2018). Tidak hanya jenis minumannya saja yang memiliki kekhasan, cara masyarakat menikmati Tuak di Kota Berastagi juga memiliki ciri khas tersendiri. Umumnya masyarakat menikmati Tuak dengan cara berkumpul bersama di Pakter Tuak (Tempat usaha Tuak) dan dengan bernyanyi lagu tradisional bersama yang diiringi gitar. Ketua PHRI Kab. Karo juga sepakat dengan suasana yang tercipta dari kebersamaan masyarakat lokal dalam menikmati minuman Tuak dapat menjadi salah satu atraksi wisata yang dinikmati wisatawan.

Aktivitas wisata malam di Kota Berastagi masih terbatas dengan kegiatan kuliner saja, padahal kesenian dan budaya Karo yang dimiliki masyarakat sangat potensial untuk dikembangkan. Kepala Bidang Pengembangan Pemasaran pada Dinas Pariwisata dan Kebudayaan Kab. Karo menuturkan bahwa minimnya keragaman atraksi wisata malam yang ada di Kota Berastagi disebabkan oleh rendahnya minat wisatawan untuk melakukan aktivitas pada malam hari. Namun dalam hal ini ketua PHRI Kab. Karo dan Ketua Lakonta yang juga Pemimpin Sanggar Seni Karo Persada memiliki pandangan yang berbeda. Kedua orang tersebut mengatakan optimis bahwa minat wisatawan untuk melakukan wisata malam di Kota Berastagi akan meningkat hanya jika atraksi yang ditawarkan lebih beragam. Terutama waktu malam hari merupakan saat yang tepat untuk menikmati hiburan, melakukan kegiatan-kegiatan ringan, bersantai danmemanjakan diri(Ngesan \& Karim, 2012). Budaya karo memiliki beragam kesenian yang dapat ditampilkan sebagai bagian dari atraksi wisata malam seperti tarian, lagu, dan musik tradisional. Para seniman dan budayawan Karo sangat terbuka dengan kemungkinan ini. Selain untuk menghadirkan keragaman atraksi wisata malam, penampilan kesenian tradisional juga dapat menjadi wadah pelestarian budaya yang dilakukan oleh masyarakat 


\section{Simpulan}

Kota Berastagi merupakan kota berbudaya yang masih berpegang teguh dengan nilai-nilai budaya Karo. Kehadiran lembaga adat dan tradisi yang masih dilakukan hingga saat ini dapat dimanfaatkan sebagai kekuatan dan proteksi sosial terhadap dampak negatif wisata malam sehingga tetap sejalan dengan kearifan lokal masyarakat. Perlu adanya kegiatan pengabdian lebih lanjut untuk melaksanakan pendampingan pada sanggar-sanggar yang melestarikan seni tradisional Suku Karo yang ada di Kota Berastagi untuk mendukung pengembangan wisata malam Kota Berastagi. Optimisme dan keterbukaan pemikiran yang dimiliki para pedagang pada wisata malam, Seniman, dan Budayawan yang ada di Kota Berastagi akan memudahkan berjalanannya kegiatan pendampingan yang dilakukan pada masa mendatang.

\section{Referensi}

Aytuğ, H. K., \& Mikaeili, M. (2017). Evaluation of Hopa's Rural Tourism Potential in the Context of European Union Tourism Policy. Procedia Environmental Sciences, 37, 234-245. https://doi.org/10.1016/j.proenv.2017.03.039

Bălan, M., \& Burghelea, C. (2015). Rural Tourism and its Implication in the Development of the Fundata Village. Procedia - Social and Behavioral Sciences, 188, 276-281. https://doi.org/10.1016/j.sbspro.2015.03.393

Damasdino, F., Parsidi, Saputra, A. D., Sinangjoyo, N. J., Ariani, A., Anwari, H., \& Islami, M. E. N. (2020). Pelatihan Mengelola Homestay di Desa Wisata Donokerto. Jurnal Abdimas Pariwisata, 1(1), 26-32. https://www.amptajurnal.ac.id/index.php/JAP/article/download/286/195\%0A

Farhan, H., \& Anwar, K. (2016). The Tourism Development Strategy Based on Rural and Local Wisdom. Journal of Sustainable Development, 9(3), 170-181. https://doi.org/10.5539/jsd.v9n3p170

Glaesser, D., Kester, J., Paulose, H., Alizadeh, A., \& Valentin, B. (2017). Global travel patterns: An overview. Journal of Travel Medicine, 24(4), 1-5. https://doi.org/10.1093/jtm/tax007

Goh, H. C. (2015). Nature and Community-based tourism (CBT) for poverty alleviation: A case study of Lower Kinabatangan, East Malaysia. Malaysian Journal of Society and Space, 11(3), 42-52. http://ejournals.ukm.my/gmjss/article/download/18524/5879

Jupir, M. M. (2013). Implementasi Kebijakan Pariwisata Berbasis Kearifan Lokal. of Indonesian Tourism and Development Studies, 1(1), 28-38. https://www.jitode.ub.ac.id/index.php/jitode/article/viewFile/105/99

Kiswantoro, A., Rohman, H., \& Susanto, D. R. (2020). Penyaluran Alat Pencegahan dan Sosialisasi Protokoler Kesehatan untuk Pelayanan Kunjungan Wisatawan dalam Menghadapi New Normal Pasca Pandemi Covid-19. Jurnal Abdimas Pariwisata, 1(2), 38-51. https://www.amptajurnal.ac.id/index.php/JAP/article/download/342/230

Lee, S. H., Chang, S. C., Hou, J. S., \& Lin, C. H. (2008). Night market experience and image of temporary residents and foreign visitors. International Journal of Culture, Tourism and Hospitality Research. https://doi.org/10.1108/17506180810891591

Markwick, M. (2018). Valletta ECoC 2018 and cultural tourism development. Journal of Tourism and Cultural Change, 16(3), 286-308. https://doi.org/10.1080/14766825.2017.1293674

Ngesan, M. R., \& Karim, H. A. (2012). Night Time Social Behavior in Urban Outdoor Spaces of Shah Alam. Procedia - Social and Behavioral Sciences, 50, 959-968. https://doi.org/10.1016/j.sbspro.2012.08.097

Nofre, J., Giordano, E., Eldridge, A., Martins, J. C., \& Sequera, J. (2018). Tourism, nightlife and planning: challenges and opportunities for community liveability in La Barceloneta. Tourism Geographies, 20(3), 377-396. https://doi.org/10.1080/14616688.2017.1375972 
Roberts, M., \& Eldridge, A. (2007). Quieter, safer, cheaper: Planning for a more inclusive evening and night-time economy. Planning Practice and Research, 22(2), 253-266.

https://doi.org/10.1080/02697450701584410

Rodrigues, A. L. O., Rodrigues, A., \& Peroff, D. M. (2015). The Sky and Sustainable Tourism Development: A Case Study of a Dark Sky Reserve Implementation in Alqueva. International Journal of Tourism Research, 17(3), 292-302. https://doi.org/10.1002/jtr.1987

Singsomboon, T. (2014). Tourism promotion and the use of local wisdom through creative tourism process. IJBTS International Journal of Business Tourism and Applied Sciences, 2(2), 32-37. https://doi.org/10.1007/s10529-009-0096-0

Veronica, S., Ginting, N., \& Marisa, A. (2019). Kajian Aspek Ekonomi pada Wisata Malam Berastagi Berbasis Kearifan Lokal. Prosiding Temu Ilmiah IPLBI 2019, 36-43. https://doi.org/https://doi.org/10.32315/ti.8.c036

Vitasurya, V. R. (2016). Local Wisdom for Sustainable Development of Rural Tourism, Case on Kalibiru and Lopati Village, Province of Daerah Istimewa Yogyakarta. Procedia - Social and Behavioral Sciences, 216(6), 97-108. https://doi.org/10.1016/j.sbspro.2015.12.014

Widiastini, N. M., Rahmawati, P. I., \& Koma, F. Y. I. (2020). RAGAM BRANDING DESA DALAM MENGEMBANGKAN Pendahuluan. Jurnal Master Pariwisata, 7(1), 195-220. https://ojs.unud.ac.id/8bd3dcbb-6077-476f-b20b-5cf0f5ec6ae2\%0A

Wolifson, P. (2016). Encountering The Night with Mobile Methods. Geographical Review, 106(2), 174-200. https://doi.org/10.1111/j.1931-0846.2015.12154.x

Wolifson, P., \& Drozdzewski, D. (2017). Co-opting the Night: The Entrepreneurial Shift and Economic Imperative in NTE Planning. Urban Policy and Research, 35(4), 486-504. https://doi.org/10.1080/08111146.2016.1155983

Yeo, S. J., \& Heng, C. K. (2014). An (Extra)ordinary Night Out: Urban Informality, Social Sustainability and the Night-time Economy. Urban Studies, 51(4), 712-726. https://doi.org/10.1177/0042098013489743

Zaki, S. A., \& Ngesan, M. R. (2012). A Future Town Redesigned - How Movement Pattern is Affected with the Concept of Night City. Procedia - Social and Behavioral Sciences. https://doi.org/10.1016/j.sbspro.2012.03.023 